\title{
RENAL THROMBOSIS COMPLICATING PINK DISEASE: CURE BY NEPHRECTOMY
}

BY

\author{
W. G. Q. MILLS and T. K. OWEN \\ From the Royal Victoria Hospital, Bournemouth
}

(RECEIVED FOR PLBLICATION APRIL 13, 1953)

Renal thrombosis is an uncommon complication of pyelitis in infancy. A record is therefore presented of the following case, in which a cure was obtained by surgical excision of an infarcted kidney, occurring in the course of pyelitis complicating pink disease.

\section{Case Report}

S.R., age 18 months, was admitted in April, 1952, giving a typical history of pink disease of six weeks' duration. Her further progress was variable and the course of the illness was complicated by intercurrent infections. In May she had gastro-enteritis, and was treated with chloromycetin. In July she had a severe upper respiratory tract infection, severe ulceration of toes and fingers, and right lower lobe pneumonia. This was treated by aureomycin. In August she had severe ulceration of the mouth and tongue, with a large slough on the anterior third of the tongue. On August 16 she developed a severe attack of pyelitis, the urine containing Bact. coli and Proteus. Aureomycin was given again, but the child's condition remained very poor. She became extremely emaciated and had large ukcers in the mouth and on the extremities. On September 18 she suddenly collapsed, and although she improved with stimulants, she developed aspiration pneumonia, again treated by aureomycin. On September 22 her condition was very poor, and she had gross haematuria. The blood urea level was $111 \mathrm{mg}$. \%, and Bact. coli was present in the urine. On September 23 a hard irregular mass was first felt in the left renal angle. A tentative diagnosis of renal embryoma (Wilms' tumour) was made. On September 29 the left kidney was removed. The child slowly improved after the operation, although Proteus persisted in the urine for some time. When seen in November she was perfectly well and had gained $2 \mathrm{lb}$. in weight.

Pathological Report. The kidney (Figs. 1 and 2) was enlarged, dark red and engorged (weight, $136 \mathrm{~g}$., expected normal weight, $43 \mathrm{~g} . ; 8.5 \times 5.5 \times 5.0 \mathrm{~cm}$. in maximum diameters).

The capsule was slightly thickened and its inner surface was lined by a layer of partially organized inflammatory exudate. The renal parenchyma cut easily and the central portion was composed of congested tissue in which there were many pale, greyish-yellow areas of infarction surrounded by haemorrhagic zones. Towards the hilum

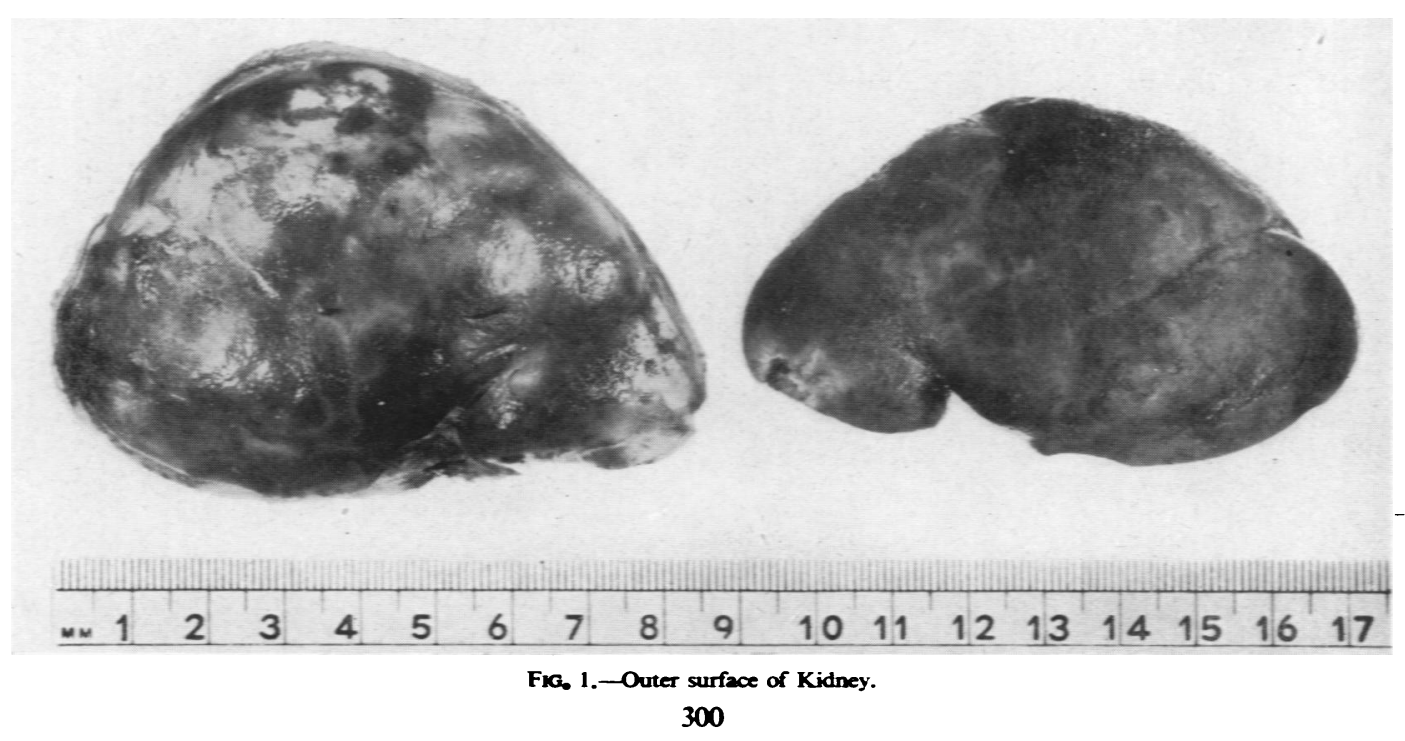


many thrombosed veins were visible, but no arterial abnormality could be seen. Microscopic examination showed areas of recent haemorrhage, areas of complete infarction, and small zones of surviving parenchyma,

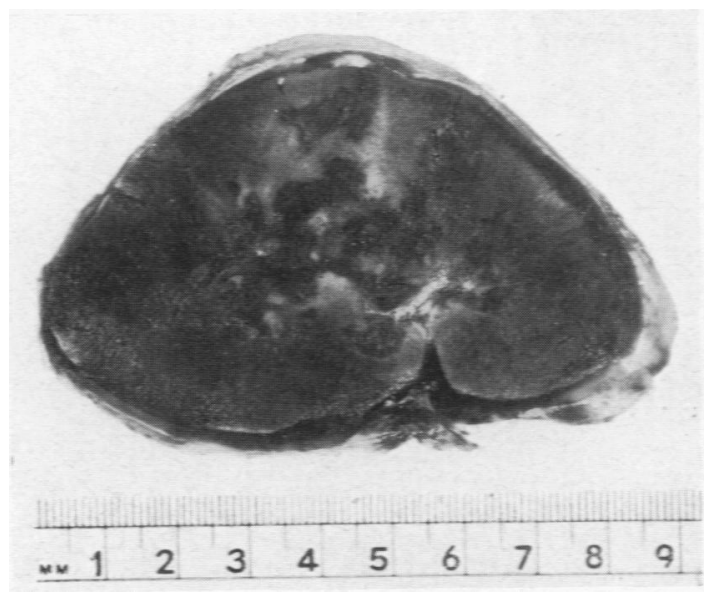

Fig. 2-Cut surface of Kidney.

which were infiltrated diffusely with inflammatory cells and in which there was considerable interstitial oedema. Collections of organisms were present in some of the infarcted tissue and in several small arterioles. Most veins were abnormal and contained ante-mortem thrombus, some of which was recent, but some showed early organization. The arteries and arterioles in general were very much less affected than the veins, and quite a high proportion of them were entirely normal. The pelvic tissues were acutely inflamed, and the small veins deep to the pelvic epithelium were thrombosed.

It was concluded that the condition was venous thrombosis supervening on acute (probably haematogenous) pyelonephritis.

\section{Discussion}

Campbell and Matthews (1942) reviewed the literature concerning renal thrombosis in infancy, and reported two cases successfully cured by nephrectomy. In their first patient, aged 13 days, a tentative diagnosis of Wilms' tumour was made, as in the case here reported, but in their second, aged 33 days, a pre-operative diagnosis of renal thrombosis was confirmed. They pointed out that the condition was not as rare as the sporadic cases reported in the literature would suggest, and that many cases pass unrecognized under the inadequate diagnosis of acute pyelitis or profound sepsis. Without operation, the prognosis is extremely grave, but it is possible that survival may occasionally occur, resulting in the unilateral scarred, atrophied kidney that is sometimes found in adult life.

Sandblom (1948) reported the successful removal of an infarcted kidney from a 5-day-old infant. He attributed the thrombosis of the renal veins to birth trauma by a difficult forceps delivery. He points out that renal infarction in children appears in two forms with different aetiology, (1) secondary to birth trauma, and, (2) the more common form, secondary to infection with debydration. Kobernick, Moore and Wiglesworth (1951) reported four further cases, all diagnosed at necropsy, aged 3 weeks, 14 months, 2 months and 1 month. The present case is the fourth recorded successfully treated by operation, and with the exception of the second case of Kobernick et al., we have not found any record of the condition occurring in the second year of life.

In our case the child had been suffering from Bact. coli and Proteus pyelitis for a little over four weeks, when she suddenly collapsed. It is probable that it was at this stage that the infection spread to a branch of the renal vein, initiating the thrombosis. Four days later severe haematuria was noted, and the next day a hard mass was felt in the loin.

Attention is drawn to the fact that if a hard mass suddenly becomes apparent in the loin of an infant suffering from pyelitis, it may be due to renal vein thrombosis, and the condition is amenable to surgery.

We wish to express our thanks to Dr. D. W. Beynon, under whose care the child was admitted, for the clinical notes, and to Dr. R. C. B. Pugh of the Hospital for Sick Children, Great Ormond Street, London, for help with the pathological report and the photographs.

\section{REFERENCES}

Campbell, M. F. and Matthews, W. F. (1942). J. Pediat., 20, 604. Kobernick, S. D., Moore, J. R. and Wiglesworth, F. W. (1951) Amer. J. Path., 27, 435.

Sandblom, P. (1948). Acta. paediat., L'ppsala, 35. 160. 